\title{
What Do We Know About Steroids Metabolism and 'PK/PD Approach' in AKI and CKD Especially While on RRT - Current Status in 2014
}

\author{
Patrick M. Honoré ${ }^{a}$ Rita Jacobs ${ }^{a}$ Elisabeth De Waele ${ }^{a} \quad$ Jouke De Regt ${ }^{a}$ \\ Thomas Rose $^{\mathrm{a}}$ Viola Van Gorp ${ }^{\mathrm{a}}$ Olivier Joannes-Boyau ${ }^{\mathrm{b}}$ Willem Boer ${ }^{\mathrm{c}}$ \\ Herbert D. Spapen ${ }^{a}$

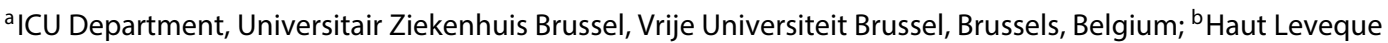 \\ University Hospital of Bordeaux, University of Bordeaux 2, Pessac, France; ' ${ }^{C}$ ntensive Care Department, Ziekenhuis \\ Oost Limburg, Genk, Belgium
}

\section{Key Words}

ICU · Translational medicine · Steroids · Pharmacokinetics · $\mathrm{PK} / \mathrm{PD} \cdot$ Renal elimination · Extra-renal removal · Dialysis · CRRT

\footnotetext{
Abstract

The knowledge on PK behavior of steroid drugs such as prednisolone or prednisone has indeed been expanding but at a rather slow pace. First, convenient, rapid, and specific determination of plasma levels of these steroids was largely indebted to the breakthrough of high performance liquid chromatography (HPLC). Second, prednisolone is non-linearly protein-bound. Since unbound prednisolone is the biologically active compound, only the measurement of this free fraction in plasma is relevant. Third, the short half-life of prednisolone precludes to reach steady-state levels and requires determination of the area under the concentrationtime curve. Fourth, prednisolone and prednisone are mutually convertible. Intravenous prednisolone, however, is administered as a pro-drug ester, which renders comparison
}

and interpretation of reported PK data of both agents unreliable. A poignant lack of awareness and knowledge regarding catabolism, clearance mechanisms, and elimination route of steroids fuels the ongoing controversy that surrounds adjunctive corticosteroid therapy in patients with chronic or acute inflammatory disease. This particular patient population is also more prone to develop early and significant kidney dysfunction, necessitating extra-renal support. A better understanding of steroid PK/PD, preferentially guided by HPLC measurement of plasma steroid concentrations, likely will have direct clinical implications, for instance by adapting steroid doses in IHD or implementing higher dose regimens during CRRT.

(c) 2014 S. Karger AG, Basel

\section{Scope of the Problem}

Pharmacokinetics/Pharmacodynamics (PK/PD) has been a very neglected domain for many decades and therefore, we would like to take the opportunity to draw atten-

\section{KARGER}

E-Mail karger@karger.com www.karger.com/bpu
(C) 2014 S. Karger AG, Basel

0253-5068/14/0382-0154\$39.50/0
Prof. Patrick M. Honoré, MD, PhD, FCCM

ICU Department, University Hospital Brussels Vrije Universiteit Brussel - VUB University

Laarbeeklaan 101, BE-1090 Brussels (Belgium)

E-Mail Patrick.Honore@uzbrussel.be 
tion to an often overlooked, yet very important aspect of steroid metabolism: steroid pharmacokinetics (PK). The knowledge on PK behavior of steroid drugs such as prednisolone or prednisone has indeed been expanding but at a rather slow pace. First, convenient, rapid, and specific determination of plasma levels of these steroids was largely indebted to the breakthrough of high performance liquid chromatography (HPLC). Second, prednisolone is nonlinearly protein-bound. Since unbound prednisolone is the biologically active compound, only the measurement of this free fraction in plasma is relevant. Third, the short half-life of prednisolone precludes to reach steadystate levels and requires determination of the area under the concentration-time curve. Fourth, prednisolone and prednisone are mutually convertible. Intravenous prednisolone, however, is administered as a pro-drug ester, which renders comparison and interpretation of reported PK data of both agents unreliable. Finally, total body clearance of prednisolone, and to a lesser extent, only the unbound fraction directly correlates with increasing concentrations of prednisolone. To be valid, steroid PK studies should therefore at least aim at standardization of drug dose, profile, and hydrosolubility.

\section{Basic Pharmacology Properties}

Some 'basic' PK information is available regarding the three clinically most used steroids: prednisone, methylprednisolone, and dexamethasone [1, 2]. Molecular weight respectively is 360,370 , and 390 Dalton $[1,2]$. The degree of protein (mainly transcortin and albumin) binding is 77,75 , and $65 \%$, respectively. Since this does not exceed $80 \%$, all steroids are removed by continuous renal replacement therapy (CRRT) and intermittent hemodialysis (IHD). Volume of distribution is $0.6,1.2$, and $0.9 \mathrm{l} / \mathrm{kg}$, respectively, remaining within the range of IHD and CRRT removal. Distribution volumes for all given steroids may even be lower because the 'older' lipophilic formulas have been replaced by the hydrosoluble forms.

The scarce PK data on methylprednisolone point out that $65-70 \%$ of the drug is eliminated daily by a normal kidney $[1,2]$. From a PK viewpoint, it thus seems appropriate to administer a higher dose for compensating drug loss during CRRT. Though never investigated in vivo, this might significantly challenge interpretation of clinical landmark studies that assessed the effects of methylprednisolone treatment in the critically ill (e.g., the ADRENAL study on adjunctive methylprednisolone treatment in septic shock [3]).

Steroids Metabolism and 'PK/PD

Approach' in AKI

\section{More Relevant Pharmacokinetic Properties}

In addition, many other PK-related observations may have clinical relevance. To cite a few: PK dose-dependency partly explaining why an alternate-day regimen with prednisone yields fewer biological effects; conversion of prednisone into prednisolone not being a limiting factor, even when liver function is severely impaired; hypoproteinemia in se not enhancing unbound concentrations of prednisolone in vivo; patients with hepatic or renal failure, elderly subjects, and renal transplant recipients showing increased unbound prednisolone concentrations.

Importantly, $\mathrm{PK}$ values are also influenced by dose magnitude (e.g., the distribution volume of methylprednisolone significantly augments with increasing dose [4]). Finally, transcortin and albumin levels may considerably vary between patients thereby producing divergent-free, steroid concentrations despite the use of similar dose regimens [4].

\section{Endogenous Relevant Pharmocokinetics}

Considerable attention has been accorded to endogenous steroid PK. However, the exogenous metabolism and in particular, the elimination route of steroids has been poorly studied $[1,2]$. The liver plays a preponderant role in steroid metabolism. Yet, several studies also divulged a key role for the kidney [4-6]. Unfortunately, we are confronted with a lot of uncertainty. Different types of steroids indeed have highly different elimination routes. Virtually no data exist regarding renal handling of steroids in chronic kidney disease and, as mentioned earlier $[1,2]$, on steroid elimination or metabolism during IHD and CRRT. The PK of methylprednisolone and prednisolone was evaluated in 24 healthy male subjects treated with single or multiple doses orally for 3 days. For each drug, 6 different dose regimens (ranging from 1 to $80 \mathrm{mg}$ of methylprednisolone and 1.25 to $100 \mathrm{mg}$ of prednisolone) and administration intervals ranging from 3 to $24 \mathrm{~h}$ were investigated [5]. Plasma was assayed using a normal phase HPLC method. Methylprednisolone expressed linear PK with no apparent dose- or time-dependency. In contrast, prednisolone showed marked dose dependency with higher clearance and volume of distribution for higher doses. The latter is explained by its saturable plasma protein-binding because clearance and distribution volume of unbound drug were not dose-dependent. After multiple dosing, prednisolone displayed a time-dependent $\mathrm{PK}$ profile with increased unbound clearance and volume of distribution [5]. 
Table 1. PK-PD of the most important steroids - elaborated from references [8-10]

\begin{tabular}{|c|c|c|c|c|c|c|}
\hline Steroids & $\begin{array}{l}\text { Molecular } \\
\text { weight, } \\
\text { daltons }\end{array}$ & $\begin{array}{l}\text { Protein } \\
\text { bounding, } \\
\%\end{array}$ & $\begin{array}{l}\text { Volume } \\
\text { of distribution, } \\
\text { l/kg }\end{array}$ & $\begin{array}{l}\text { Approximate } \\
\text { target concentration } \\
\text { (huge discrepancies } \\
\text { between studies), } \\
\text { mcg/dl }\end{array}$ & $\begin{array}{l}\text { Elimination by } \\
\text { CRRT - sieving }\end{array}$ & $\begin{array}{l}\text { Dose recommended } \\
\text { under CRRT } \\
\text { (increase in \%) }\end{array}$ \\
\hline Prednisone & 360 & 77 & 0.6 & 10 & sieving of 0.90 & $\begin{array}{l}\text { Increase daily dose } \\
\text { by } 100 \% \text { per day } \\
\text { under CRRT }\end{array}$ \\
\hline Methylprednisolone & 370 & 75 & 1.2 & $15-20$ & sieving of 0.80 & $\begin{array}{l}\text { Increase daily dose } \\
\text { by } 70 \% \text { per day under } \\
\text { CRRT }\end{array}$ \\
\hline Dexamethasone & 390 & 65 & 0.9 & $50-100$ & sieving of 0.95 & $\begin{array}{l}\text { Increase daily dose } \\
\text { by } 110 \% \text { per day } \\
\text { under CRRT }\end{array}$ \\
\hline
\end{tabular}

\section{‘PK/PD Approach' During AKI, CKD and RRT}

Such complex pharmacokinetic behavior obviously thwarts any attempt to reliably determine prednisolone doses needed to obtain a desired target concentration in the presence of AKI and/or extra-renal depuration. With concentrations proportional to the given dose, the PK of methylprednisolone is more predictable. Thus, the assessment of methylprednisolone plasma protein binding is less important in patients undergoing IHD or CRRT. Sieving coefficients, target concentrations (difficult to upraise as there are huge discrepancies between studies) and CRRT elimination percentages are provided in a dedicated table (table 1).

Methylprednisolone PK and its direct suppressive effects on cortisol secretion and cell trafficking were compared in 6 patients with chronic renal failure (CRF) and in 6 healthy controls [6]. Intravenous administration of $0.6 \mathrm{mg} / \mathrm{kg}$ methylprednisolone produced similar PK in both groups. Clearance approximated $280 \mathrm{ml} / \mathrm{h} / \mathrm{kg}$, and the volume of distribution, $t_{1 / 2}$ and unbound fraction were respectively $1.1 \mathrm{l} / \mathrm{kg}, 2.7 \mathrm{~h}$, and 0.20 [6]. Treatment with methylprednisolone may thus offer a therapeutic advantage in CRF patients since all other corticosteroids display altered PK characteristics in this condition.

Other processes besides renal elimination may be responsible for an observed decrease in plasma steroid concentrations. A study in patients with rheumatoid arthritis and systemic lupus erythematosus demonstrated that inadequately low serum levels of adrenal androgens and cortisol were not due to the increased renal clearance and daily loss of these hormones but resulted from decreased adrenal production or increased conversion or conjugation to downstream hormones [7].

\section{The Case of Hydrocortisone}

Some 'basic' PK information is available regarding hydrocortisone as well. Its molecular weight is 362 daltons [8]. The degree of protein (mainly transcortin and albumin) binding is $78 \%$ [8]. Since this does not exceed $80 \%$, all steroids are removed by the continuous renal replacement therapy (CRRT) and intermittent hemodialysis (IHD). The volume of distribution is the lowest with 0.5 $1 / \mathrm{kg}$ [8]. As a result, hydrocortisone is even more rapidly eliminated by CRRT and IHD when compared to other steroids. Sieving coefficient and CRRT elimination is provided in a dedicated table (table 1 ).

\section{Conclusions and Perspectives}

In conclusion, a poignant lack of awareness and knowledge regarding catabolism, clearance mechanisms and elimination route of steroids fuels the ongoing contro- 
versy that surrounds adjunctive corticosteroid therapy in patients with chronic [7] or acute [8-10] inflammatory disease. This particular patient population is also more prone to develop early and significant kidney dysfunction, necessitating extra-renal support. A better under- standing of steroid PK, preferentially guided by HPLC measurement of plasma steroid concentrations, likely will have direct clinical implications, for instance by adapting steroid doses in IHD or implementing higher dose regimens during CRRT.

\section{References}

1 Sefar S, Degoricija V: About drug dialyzability. Acta Clin Croat 2003;42:257-267.

2 Al-Habet SM, Rogers HJ: Methylprednisolone pharmacokinetics after intravenous and oral administration. Br J Clin Pharmacol 1989;27: 285-290.

- 3 Venkatesh B, Myburgh J, Finfer S, Webb SA, Cohen J, Bellomo R, McArthur C, Joyce CJ, Rajbhandari D, Glass P, Harward M; ANZICS CTG investigators: The ADRENAL study protocol: adjunctive corticosteroid treatment in critically ill patients with septic shock. Crit Care Resusc 2013;15:83-88.
4 Frey BM, Frey FJ: Clinical pharmacokinetics of prednisone and prednisolone. Clin Pharmacokinet 1990;19:126-146.

5 Rohatagi S, Barth J, Möllmann H, Hochhaus G, Soldner A, Möllmann C, Derendorf H: Pharmacokinetics of methylprednisolone and prednisolone after single and multiple oral administration. J Clin Pharmacol 1997;37: 916-925.

6 Jusko WJ, Milad MA, Ludwig EA, Lew KH, Kohli RK: Methylprednisolone pharmacokinetics and pharmacodynamics in chronic renal failure. Clin Nephrol 1995;43(suppl 1):S16-S19.

7 Straub RH, Weidler C, Demmel B, Herrmann M, Kees F, Schmidt M, Schölmerich J, Schedel $\mathrm{J}$ : Renal clearance and daily excretion of cortisol and adrenal androgens in patients with rheumatoid arthritis and systemic lupus erythematosus. Ann Rheum Dis 2004;63:961-968.
8 Simon N, Castinetti F, Ouliac F, Lesavre N, Brue T, Oliver C: Pharmacokinetic evidence for suboptimal treatment of adrenal insufficiency with currently available hydrocortisone tablets. Clin Pharmacokinet 2010;49: 455-463.

9 Batzofin BM, Sprung CL, Weiss YG: The use of steroids in the treatment of severe sepsis and septic shock. Best Pract Res Clin Endocrinol Metab 2011;25:735-743.

10 Toma A, Stone A, Green RS, Gray S: Steroids for patients in septic shock: the results of the CORTICUS trial. CJEM 2011;13:273-276. 